\title{
Perioperative medical management for patients with RA, SPA, and SLE undergoing total hip and total knee replacement: a narrative review
}

\author{
Susan M. Goodman *iD and Anne R. Bass
}

\begin{abstract}
Total hip (THA) and total knee arthroplasty (TKA) are widely used, successful procedures for symptomatic end stage arthritis of the hips or knees, but patients with rheumatoid arthritis (RA), systemic lupus erythematosus (SLE), and spondyloarthritis (SPA) including ankylosing spondylitis (AS) and psoriatic arthritis (PSA) are at higher risk for adverse events after surgery. Utilization rates of THA and TKA remain high for patients with RA, and rates of arthroplasty have increased for patients with SLE and SPA. However, complications such as infection are increased for patients with SLE, RA, and SPA, most of whom are receiving potent immunosuppressant medications and glucocorticoids at the time of surgery. Patients with SLE and AS are also at increased risk for perioperative cardiac and venous thromboembolism (VTE), while RA patients do not have an increase in perioperative cardiac or VTE risk, despite an overall increase in VTE and cardiac disease. This narrative review will discuss the areas of heightened risk for patients with RA, SLE, and SPA, and the perioperative management strategies currently used to minimize the risks.
\end{abstract}

Keywords: Total hip arthroplasty, Total knee arthroplasty, Rheumatoid arthritis, Systemic lupus erythematosus, Spondyloarthritis, Perioperative infection, Cardiac risk, Venous-thromboembolism

\section{Background}

Total hip (THA) and total knee arthroplasty (TKA) remain valuable options to relieve pain and improve function caused by end-stage arthritis of the hip and knee, including for patients with rheumatoid arthritis (RA), Spondyloarthritis (SPA) including ankylosing spondylitis(AS) and psoriatic arthritis (PSA) and systemic lupus erythematosus (SLE). While rates of THA and TKA for patients with osteoarthritis have increased markedly over the past decade, projections suggest even further increases in utilization by 2015 [1,2]. Large joint arthroplasty rates for patients with rheumatoid arthritis (RA) have remained stable while rates of arthroplasty for patients with spondyloarthritis (SPA) have increased by $50 \%$, and rates have doubled for patients with systemic lupus erythematosus (SLE) [3-6]. The increased utilization of potent disease

\footnotetext{
*Correspondence: Goodmans@hss.edu

Department of Medicine, Weill Cornell Medical School, Division of

Rheumatology Hospital for Special Surgery, 535 E 70th St, New York City, NY 10021, USA
}

modifying anti-rheumatic drugs (DMARDs) and biologics like the tumor necrosis factor inhibitors (TNFi) has had a clear impact on quality of life for patients with RA, SPA, and SLE, medication use has not been shown to decrease the incidence of large joint arthroplasty for RA, and most RA, PSA, and SLE patients are receiving these immunosuppressant medications at the time of surgery [6-8]. While improvements in pain and function outcomes measured pre and post-operatively are excellent after THA and TKA for patients with RA, , and SLE, adverse events, in particular infection, re increased [9-17]. Ninety day readmission, most mmonly for infection, is also increased for patients h RA [18]. Other adverse events increased in pats with SLE include deep venous thrombosis (DVT) pulmonary embolism (PE), and major acute coronevents (MACE), although patients with RA do not increased risk for VTE or MACE after arthroplasty $[19,20]$. While the recent literature addressing adverse events in patients with SPA is sparse, increased 
inpatient complications including VTE and cardiac complications have been described using the Agency for Healthcare Research and Quality National Inpatient Sample, a large publically available inpatient database [21], while older studies have demonstrated an increase in infection for patients with PSA undergoing arthroplasty, but have not been repeated since the use of prophylactic perioperative antibiotics became widespread [22, 23]. For patients with RA, the RA specific experience of the surgeon or surgical team decreases the risk of adverse surgical events, but the volume-outcome relationship with SLE or SPA specific volume has not been described [24]. This review will discuss the increased infectious, cardiac, and thromboembolic adverse events seen after THA and TKA in patients with RA, SPA, and SLE, and the perioperative medical evaluation and management options to decrease risk.

\section{Infection}

Infection is the most common cause for prosthetic joint failure, and the overall risk of infection is increased in patients with RA, SPA, and SLE [11, 25-29]. The age standardized rate of TKA infection was $1.26 \%$ for recipients with RA, compared to $0.84 \%$ for recipients with OA, with an adjusted Hazard Ratio (HR) of 1.47, $P=0.03$, confirmed in a recent meta-analysis demonstrating a relative risk of 1.7 for patients with RA [11, 29]. For patients with SLE whose disease was severe enough to warrant hospitalization within 6 months of surgery, a large study based on Taiwan's National Health Insurance Research Database found the risk of septicaemia to be markedly increased after surgeries including orthopedic procedures $(\mathrm{OR}=3.43,95 \%$ CI 2.48 to 4.74) [14]. Immunosuppressant medications including biologics and DMARDs used to treat RA, SPA, and SLE are recognized to increase the risk of infection [30]. Nonetheless, the majority of patients with RA, SPA, and SLE are taking DMARDs, biologics, or other potent immunosuppressant medications at the time of surgery $[10,16,31,32]$. Medication management, including decisions to continue or withhold medication, is inconsistent, even at high volume centers with experience in arthroplasty for patients with rheumatic diseases [33]. While the increased risk of infection has been attributed to therapy with immunosuppressant medications including DMARDs and biologics, an association with post-operative infection has never been demonstrated directly in randomized controlled trials performed at the time of surgery. The relationship of post-operative infection to anti-rheumatic medication use is unproven, although [32-34] a meta-analysis has demonstrated an increased risk of infection associated with TNFi exposure around the time of surgery when data was pooled [35], a conclusion supported by additional observational studies [15, 34-36]. However, a recent study that used billing data to specify the timing of infliximab infusions in relation to surgery found no clear increase in risk of infection when infliximab was infused within 4 weeks of surgery compared to longer periods of drug withholding [34]. Disease activity and severity may contribute to the risk of peri-operative infection for RA, SPA, and SLE, and might confound the reported association with medication use [14, 37]. Use of glucocorticoids, however, has been consistently associated with an increased risk of infection in multiple settings- including surgery -at dosages above $15 \mathrm{mg}$./day, yet supraphysiologic doses of glucocorticoids ("stress dose steroids") are routinely administered on the day of surgery out of concern for hemodynamic instability $[38,39]$. Synthetic DMARDs including methotrexate, leflunomide, and sulfasalazine have not been demonstrated to increase the risk of perioperative infection, in a randomized controlled trial of perioperative methotrexate use [40].

Using a consensus based process, after analysis of an extensive literature review, The American College of Rheumatology (ACR) and The American Association of Hip and Knee Surgeons (AAHKS) have collaborated on a recently published guideline for the peri-operative management of anti-rheumatic therapy for patients with rheumatic diseases including RA, SPA, and SLE undergoing THA and TKA [41]. The recommendations weighed the risk of infection versus the risk of disease flare when medications were withheld, and were informed by the input of a patient panel that placed far greater importance on the risk of infection, concurring with the panel of experts [42]. The collaborators recommend continuing DMARDs, withholding biologics, based on the dose interval, and withholding tofacitinib for 7 days prior to surgery. Any withheld medications can be re-started after 2 weeks, if there is no evidence of infection either at the surgical site, or elsewhere, and the wound demonstrates good healing. The panel recommends administering the usual daily dose of glucocorticoid (after careful taper when possible to $<20 \mathrm{mg}$. prednisone) rather than supra-physiologic "stress dose steroids" on the day of THA or TKA, specifically for adults receiving glucocorticoids for treatment of their rheumatic condition, excluding patients with juvenile arthritis who may have received glucocorticoids during development or those patients receiving glucocorticoids for adrenal or pituitary insufficiency from this recommendation (Table 1) [41].

\section{Major acute cardiac events}

Patients with SLE, SPA, and RA have significantly increased risk of cardiac disease compared to age and sex matched controls. In studies using carotid atherosclerosis as a surrogate for coronary artery disease, patients with RA and SLE had almost 3 times more carotid atherosclerosis (RA $44 \%$ versus $15 \%, p=.001$; SLE $37.1 \%$ vs. $15.2 \%$, 
Table 1 Medicatons included in this guideline ${ }^{a}$

\begin{tabular}{|c|c|c|}
\hline DMARDs: CONTINUE these medications through surgery. & Dosing Interval & Continue/Withhold \\
\hline Methotrexate & Weekly & Continue \\
\hline Sulfasalazine & Once or twice daily & Continue \\
\hline Hydroxychloroquine & Once or twice daily & Continue \\
\hline Leflunomide (Arava) & Daily & Continue \\
\hline Doxycycline & Daily & Continue \\
\hline $\begin{array}{l}\text { BIOLOGICS: STOP these medications prior to surgery and } \\
\text { schedule surgery at the end of the dosing cycle. RESUME } \\
\text { medications at minimum } 14 \text { days after surgery in the } \\
\text { absence wound healing problems, surgical site infection } \\
\text { or systemic infection. }\end{array}$ & Dosing Interval & $\begin{array}{l}\text { Schedule Surgery (relative to last } \\
\text { biologic dose administered) }\end{array}$ \\
\hline Adalimumab (Humira) 40 mg & Every 2 weeks & Week 3 \\
\hline Etanercept (Enbrel) $50 \mathrm{mg}$ or $25 \mathrm{mg}$ & Weekly or twice weekly & Week 2 \\
\hline \multirow[t]{2}{*}{ Golimumab (Simponi)50 mg } & Every 4 weeks (SQ)or & Week 5 \\
\hline & Every 8 weeks (IV) & Week 9 \\
\hline Infliximab (Remicade)3 mg/kg & Every 4,6 , or 8 weeks & Week 5,7 , or 9 \\
\hline Abatacept (Orencia) weight-based 500 mg; IV 1000 mg; SQ & Monthly (IV)or & Week 5 \\
\hline $125 \mathrm{mg}$ & Weekly (SQ) & Week 2 \\
\hline Rituximab (Rituxan)1000 mg & 2 doses 2 weeks apart every $4-6$ months & Month 7 \\
\hline Tocilizumab (Actemra) IV 4 mg/kg; & Every week (SQ) or Every 4 weeks & Week 3 \\
\hline SQ 162 mg & (IV) & Week 5 \\
\hline Anakinra (Kineret) SQ 100 mg & Daily & Day 2 \\
\hline Secukinumab (Cosentyx) $150 \mathrm{mg}$ & Every 4 weeks & Week 5 \\
\hline Ustekinumab (Stela) 45 mg & Every 12 weeks & Week 13 \\
\hline Belimumab (Benlysta) 10 mg/kg & Every 4 weeks & Week 5 \\
\hline Tofacitinib (Xeljanz) 5 mg: STOP this medication 7 days prior to surgery. & Daily or twice daily & 7 days after last dose \\
\hline $\begin{array}{l}\text { SEVERE SLE-SPECIFIC MEDICATIONS: CONTINUE these medications in } \\
\text { the perioperative period. }\end{array}$ & Dosing Interval & Continue/Withhold \\
\hline Mycophenolate & Twice daily & Continue \\
\hline Azathioprine & Daily or twice daily & Continue \\
\hline Cyclosporine & Twice daily & Continue \\
\hline Tacrolimus & Twice daily (IV and PO) & Continue \\
\hline $\begin{array}{l}\text { NOT-SEVERE SLE: DISCONTINUE these medications in the } \\
\text { perioperative period. }\end{array}$ & Dosing Interval & Continue/Withhold \\
\hline Mycophenolate & Twice daily & Withhold \\
\hline Azathioprine & Daily or twice daily & Withhold \\
\hline Cyclosporine & Twice daily & Withhold \\
\hline Tacrolimus & Twice daily (IV and PO) & Continue \\
\hline
\end{tabular}

Dosing intervals obtained from prescribing information provided online by pharmaceutical companies

a2016 American College of Rheumatology/American Association of Hip and Knee Surgeons Guidelines for the Perioperative Management of Anti-rheumatic Medication in Patients with Rheumatic Diseases Undergoing Elective Total Hip or Total Knee Arthroplasty. Permission to reuse given by John Wiley and Sons on August 28, 2017, License Number 4177680712679

$P<0.001)$, even after controlling for traditional cardiac risk factors $[43,44]$. For patients with $\mathrm{RA}$, the risk of $\mathrm{MI}$ is similar to that seen in patients with diabetes $[19,45,46]$. While cardiac mortality is increased by $50 \%$ for patients with RA, they are less likely to report cardiac symptoms such as chest pain [47, 48]. Traditional risk factors such as hypertension and smoking contribute to cardiac risk for patients with RA, and markers of sustained inflammation and disease severity are additional risk factors [49-51]. For patients with SLE, mortality from cardiovascular disease has continued to increase, despite improvements in mortality previously seen for patients with active SLE. The risk of death and cardiac events has doubled, with increases seen even early in the 
disease $[52,53]$. Young women with SLE between the age of 35-44 are 50 times more likely to have an MI than age matched controls [54]. While the extreme increase in relative risk for cardiovascular events is dramatic in young patients with SLE, the absolute risk of cardiovascular events is higher in older women with SLE [55]. In a multicenter Spanish SLE register, 374 (10.9\%) of patients had angina, an MI, stroke, or peripheral artery disease. In this cohort, traditional risk factors included smoking and hyperlipidemia, but hypocomplementemia was a risk factor as well, suggesting that for SLE, disease activity contributes to cardiovascular risk [56]. Others have also found that traditional risk factors alone cannot explain the increased risk, and factors such as SLE disease activity and severity contribute to cardiovascular risk [55-58].

Patients with SPA have a higher prevalence of CVD, and have a significant increase in traditional CVD risk factors including hypertension, hyperlipidemia as well as obesity [59-61]. For patients with PSA, the risk of major cardiac events is increased for those not prescribed a DMARD (HR 1.24, 95\% CI 1.03 to 1.49), suggesting that either disease severity or activity may also increase cardiac risk in PSA [62].

Perioperative cardiovascular risk is increased in those with known cardiovascular disease. In a large orthopedic hospital, post-operative myocardial infarction (MI) occurred in $0.6 \%$ of 8000 inpatient orthopedic procedures, while the risk for those with known ischemic heart disease or risk factors for ischemic heart disease increased to $6.5 \%$ [63] suggesting that patients with RA, SPA, and SLE should be at higher risk, given the increase in the prevalence of cardiac disease for these patients and the similarity in risk profile for RA patients when compared to patients with diabetes $[45,54,57,64,65]$. However, when a large insurance data-base was queried and patients with RA were compared to patients with DM after surgery, there was a substantially lower rate of cardiac events (RA 0.34\% vs. DM 1.07\%; $p<0.001$ ) and death (RA $0.30 \%$ vs. DM $0.65 \% ; p<0.001$ ) for patients with RA after intermediate risk procedures including arthroplasty [19]. In addition, there was no increase in in-hospital mortality for RA patients after arthroplasty when compared to controls [66]. However, for patients with SLE, unlike in patients with RA, perioperative risk of cardiac events and death were significantly increased in the US Nationwide Inpatient Sample, with an OR of 4.0 (95\% CI 1.9-8.0) for postoperative mortality with hip replacements and an OR of 1.2 (95\% CI $0.2-7.5)$ for mortality with knee replacements [20,66]. Increased in-hospital mortality for patients with SLE has been confirmed using discharge data from seven states, comprising 8 million discharges, with a higher risk of in-hospital mortality(OR (99\% CI) of 1.27 (1.11, 1.47); $P<.001)$, although no increase in in-hospital cardiac events were reported [67]. Similarly, 30 day post-operative mortality risk is increased in patients with SLE in a report using the Taiwan national insurance database $(\mathrm{OR}=2.39,95 \%$ CI 1.28 to 4.45) [14]. For patients with AS, the risk of in-patient cardiac events after THA was significantly higher than in controls [21].

The American Heart Association and American College of Cardiology (AHA/ACC) have formulated guidelines for assessing cardiac risk in preparation for surgery, based on a combination of functional capacity and risk factors including the presence of CAD (angina and/or prior MI), heart failure, stroke or transient ischemic attack, renal insufficiency (serum creatinine $[2 \mathrm{mg} / \mathrm{dl}$ or creatinine clearance $160 \mathrm{ml} / \mathrm{min} / 1.73 \mathrm{~m} 2$ ), and diabetes requiring insulin therapy [68]. Using this guideline in patients with RA, SPA, and SLE is complicated by the poor functional capacity of many patients prior to THA and TKA, when poor functional capacity is defined as the inability to achieve at least 4 Metabolic Equivalents (METS), achieved by light shoveling, dancing, or gardening, defining "light" as when the activity results in "only minimal perspiration and only a slight increase in breathing above normal" [69]. Moreover, patients with RA with cardiovascular disease may not have symptoms $[48,70,71]$. Using the classic Framingham risk equation (based on age, sex, total cholesterol level, high density lipoprotein cholesterol level, smoking history, and systolic blood pressure), patients with RA, SPA, and SLE may fall into a low risk category, leading some to add the presence of a systemic inflammatory disease such as RA, SPA, and SLE to the list of traditional cardiovascular risk factors, or to add a multiplication factor of 1.4 to the calculation of cardiac risk, recognizing that the current risk assessment tools are unreliable and underestimate cardiac risk in patients with RA, SPA, and SLE [51, 72-76]. Major orthopedic surgery is categorized as an intermediate risk procedure in the ACA/AHA guideline, and carries a $1-5 \%$ risk of $\mathrm{MI}$ or cardiovascular death [68]. While none of these formulations are entirely satisfactory for estimating perioperative risk in patients with inflammatory diseases, a pragmatic approach has been to include RA, SPA, and SLE as risk factors in the ACA/AHA algorithm; patients with 2 risk factors, one of which could be RA, SPA, and SLE, and poor functional capacity (< 4 METS), would undergo testing for evidence of cardiac ischemia prior to elective intermediate risk surgery.

\section{Venous Thromboembolism}

Patients with rheumatic diseases have more than double the risk of VTE compared to the general population, particularly when their disease is active [77-81]. This is not surprising given the association between inflammation and thrombosis [82]. Although RA patients have double the risk of VTE over all [83-85], RA patients 
undergoing arthroplasty are not at increased VTE risk $[11,32,85,86]$. For example, in a study of close to a billion hospitalized patients, RA and non-RA patients admitted for surgery on their joints had the same risk of postoperative VTE $(0.67 \%)$ [85]. In contrast, the RA patients admitted for other reasons had double the risk of VTE compared to their non-RA peers $(2.3 \%$ vs. $1.15 \%)$ [85]. Risk factors for postoperative VTE in RA patients in this study were similar to those in other patients and included advanced age, female gender, and African-American race. It is possible that good disease control in RA patients undergoing arthroplasty explains their relatively low VTE risk. In contrast, a recent retrospective study of patients undergoing spine surgery demonstrated a significantly higher risk of VTE in RA patients than non-RA patients [87]. Although this finding requires validation, it could also reflect the more urgent nature of spine surgery, which may not permit RA disease optimization.

Patients with SPA are at higher risk of VTE than the general population [79]. As with RA patients, however, the risk of VTE after arthroplasty does not appear to be higher in these patients. For example, in a study that looked at complication rates after TKA, there was a higher rate of DVT, but no difference in the rate of PE (or total VTE) in 4575 ankylosing spondylitis patients, and no difference in DVT or PE rates in the 7918 psoriatic arthritis compared to 1,751,938 OA controls [88].

Patients with SLE are also at higher risk for VTE [79-81, 89, 90]. Among lupus patients, VTE risk factors include smoking, obesity, hemolytic anemia and anti-phospholipid antibodies, while Asian race is protective $[89,90]$. Lupus patients who have received inpatient care for their lupus in the 6 months prior to surgery are five times more likely to experience postoperative PE [14] reinforcing the concept that it is disease activity that increases thrombotic risk. Lupus patients are also more likely than other individuals to have antiphospholipid antibodies, a well-established risk factor for VTE $[89,91]$. Among patients with antiphospholipid antibodies, those with a lupus anticoagulant (LAC) or triple positivity (LAC plus high titer anti-cardiolipin and anti-beta 2 glycoprotein 1 antibodies) are at highest VTE risk [92-94].

Current recommendations for postoperative VTE prophylaxis in patients with the antiphospholipid antibody syndrome (APS) are to minimize the time off anticoagulation, bridge with low molecular weight heparin, and resume warfarin the night of surgery [95, 96]. Although a recent prospective trial demonstrated less thrombin generation in APS patients given rivaroxaban compared to warfarin [97], there are no studies demonstrating the safety and/or efficacy of direct oral anticoagulants in preventing thrombotic events in APS. In patients with APS, surgery can sometimes act as a trigger for catastrophic antiphospholipid syndrome (CAPS). Patients with CAPS should be managed with parenteral anticoagulation and may require additional treatment with corticosteroids, IVIG and/or rituximab [98] .

It should also be remembered that, in addition to assessing the activity of their rheumatic disease, patients with RA, SPA and SLE should also be assessed for traditional VTE risk factors prior to surgery (Table 2).

Recommended prophylactic anticoagulation for (nonAPS) rheumatic disease patients whose disease is quiet is the same as for non-rheumatic disease patients. Patients with active rheumatic disease should, preferably, have their disease controlled prior to undergoing elective orthopedic surgery. Patients with active rheumatic disease who must undergo urgent surgical procedures should be considered at higher than average VTE risk; prophylaxis will depend on their particular procedure.

\section{Conclusion}

In summary, while patients with RA, SPA, and SLE continue to utilize THA and TKA, they are at higher risk for complications. Risk of infection is higher in patients with RA, SPA, and SLE, and may be decreased via perioperative medication management strategies that include withholding all biologics prior to surgery, although traditional DMARDs do not appear to increase risk of infection. Perioperative cardiac risk stratification is improved with the recognition that patients with RA, SPA, and SLE are at higher risk of

Table 2 Risk factors for venous thromboembolism in rheumatic disease patients undergoing surgery

Patient-specific risk factors
Active rheumatic disease
History of $\mathrm{VTE}^{\mathrm{a}}$
Active cancer
Estrogen
Active cancer
Smoking
Advanced age
Black race (Asian race protective)
Obesity
Non-O ABO blood group
Thrombophilia
Surgery-specific risk factors
Orthopedic surgery > other surgery
Hip fracture
Bilateral arthroplasty
Revision arthroplasty
General > Axial/regional anesthesia

${ }^{\mathrm{a}} \mathrm{VTE}=$ venous thromboembolism 
cardiac disease than age matched controls. While patients with SLE are at higher risk of VTE after surgery, VTE risk for patients with RA and SPA is no higher than for others undergoing THA and TKA. Improved outcomes may be achieved with attention to preoperative optimization to minimize perioperative risks.

\section{Acknowledgements}

Not applicable

\section{Funding}

There are no funding sources associated with this article.

\section{Availability of data and materials}

Not applicable

\section{Authors' contributions}

SMG and ARB performed the literature search, wrote and revised the manuscript, and gave final approval of the version to be published.

\section{Ethics approval and consent to participate}

Not applicable

\section{Consent for publication}

Not applicable

\section{Competing interests}

SMG is a member of the Editorial Board of BMC Rheumatology. ARB declares that she has no competing interest.

\section{Publisher's Note}

Springer Nature remains neutral with regard to jurisdictional claims in published maps and institutional affiliations.

Received: 11 September 2017 Accepted: 3 January 2018 Published online: 30 January 2018

\section{References}

1. Inacio MCS, Paxton EW, Graves SE, Namba RS, Nemes S. Projected increase in total knee arthroplasty in the United States - an alternative projection model. Osteoarthritis Cartilage. 2017; Nov;25(11):1797-803.

2. Kurtz S, Ong K, Lau E, Mowat F, Halpern M. Projections of primary and revision hip and knee arthroplasty in the United States from 2005 to 2030 . J Bone Joint Surg Am. 2007; Apr:89(4):780-5.

3. Mertelsmann-Voss C, Lyman S, Pan TJ, Goodman S, Figgie MP, Mandl LA Arthroplasty rates are increased among US patients with systemic lupus erythematosus: 1991-2005. J Rheumatol. 2014; May;41(5):867-74

4. Mertelsmann-Voss C, Lyman S, Pan TJ, Goodman SM, Figgie MP, Mandl LA US trends in rates of arthroplasty for inflammatory arthritis including rheumatoid arthritis, juvenile idiopathic arthritis, and spondyloarthritis. Arthritis Rheumatol. 2014; Jun:66(6):1432-9.

5. Sokka T, Kautiainen $H$, Hannonen P. Stable occurrence of knee and hip total joint replacement in Central Finland between 1986 and 2003: an indication of improved long-term outcomes of rheumatoid arthritis. Ann Rheum Dis. 2007: Mar:66(3):341-4.

6. Nikiphorou E, Carpenter L, Morris S, Macgregor AJ, Dixey J, Kiely P, et al. Hand and foot surgery rates in rheumatoid arthritis have declined from 1986 to 2011, but large-joint replacement rates remain unchanged: results from two UK inception cohorts. Arthritis Rheumatol. 2014; May;66(5):1081-9.

7. Aaltonen KJ, Virkki LM, Jamsen E, Sokka T, Konttinen YT, Peltomaa R, et al. Do biologic drugs affect the need for and outcome of joint replacements in patients with rheumatoid arthritis? A register-based study. Semin Arthritis Rheum. 2013; Aug;43(1):55-62.

8. Strand V, Sharp V, Koenig AS, Park G, Shi Y, Wang B, et al. Comparison of health-related quality of life in rheumatoid arthritis, psoriatic arthritis and psoriasis and effects of etanercept treatment. Ann Rheum Dis. 2012; Jul; 71(7):1143-50.
9. Shah UH, Mandl LA, Mertelsmann-Voss C, Lee YY, Alexiades MM, Figgie MP, et al. Systemic lupus erythematosus is not a risk factor for poor outcomes after total hip and total knee arthroplasty. Lupus. 2015; Jan 16;24(9):900-8.

10. Goodman SM, Johnson B, Zhang M, Huang WT, Zhu R, Figgie M, et al. Patients with Rheumatoid Arthritis have Similar Excellent Outcomes after Total Knee Replacement Compared with Patients with Osteoarthritis. J Rheumatol. 2016; Jan;43(1):46-53.

11. Ravi B, Croxford R, Hollands S, Paterson JM, Bogoch E, Kreder H, et al. Increased risk of complications following total joint arthroplasty in patients with rheumatoid arthritis. Arthritis Rheumatol. 2014; Feb;66(2):254-63.

12. Ravi B, Croxford R, Hollands S, Paterson MJ, Bogoch E, Kreder H, et al. Patients with rheumatoid arthritis are at increased risk for complications following total joint arthroplasty. Arthritis Rheum. 2013; Nov 19;66(2):254-63.

13. Singh JA, Inacio MC, Namba RS, Paxton EW. Rheumatoid arthritis is associated with higher 90-day hospital readmission rates compared to osteoarthritis after hip or knee arthroplasty: A cohort study. Arthritis Care Res (Hoboken). 2014: Oct 9:67(5):718-24.

14. Lin JA, Liao CC, Lee YJ, Wu CH, Huang WQ, Chen TL. Adverse outcomes after major surgery in patients with systemic lupus erythematosus: a nationwide population-based study. Ann Rheum Dis. 2014; Sep;73(9):1646-51.

15. Salt E, Wiggins AT, Rayens MK, Morris BJ, Mannino D, Hoellein A, et al. Moderating effects of immunosuppressive medications and risk factors for post-operative joint infection following total joint arthroplasty in patients with rheumatoid arthritis or osteoarthritis. Semin Arthritis Rheum. 2017; Feb; 46(4):423-9

16. Mandl LA, Zhu R, Huang WT, Zhang M, Alexiades MM, Figgie MP, et al. Short Term Total Hip Arthroplasty Outcomes in Patients with Psoriatic Arthritis, Psoriasis Skin Disease, and Osteoarthritis. Arthritis Rheumatol. 2015; Sep 11;68(2):410-7.

17. Goodman SM, Zhu R, Figgie MP, Huang WT, Mandl LA. Short-term total hip replacement outcomes in ankylosing spondylitis. J Clin Rheumatol. 2014; Oct;20(7):363-8.

18. Singh JA, Inacio MC, Namba RS, Paxton EW. Rheumatoid Arthritis is Associated With Higher Ninety-Day Hospital Readmission Rates Compared to Osteoarthritis After Hip or Knee Arthroplasty: A Cohort Study. Arthritis Care Res (Hoboken). 2015; May:67(5):718-24.

19. Yazdanyar A, Wasko MC, Kraemer KL, Ward MM. Perioperative all-cause mortality and cardiovascular events in patients with rheumatoid arthritis: Comparison with unaffected controls and persons with diabetes mellitus. Arthritis Rheum. 2012; Aug;64(8):2429-37.

20. Yazdanyar A, Wasko MC, Scalzi LV, Kraemer KL, Ward MM. Short-term perioperative all-cause mortality and cardiovascular events in women with systemic lupus erythematosus. Arthritis Care Res (Hoboken). 2012; Dec 4;65(6):986-91.

21. Schnaser EA, Browne JA, Padgett DE, Figgie MP, D'Apuzzo MR. Perioperative Complications in Patients With Inflammatory Arthropathy Undergoing Total Hip Arthroplasty. J Arthroplasty. 2016; Oct;31(10):2286-90

22. Stern SH, Insall JN, Windsor RE, Inglis AE, Dines DM. Total knee arthroplasty in patients with psoriasis. Clin Orthop Relat Res. 1989;248(248):108-10. discussion 111

23. Menon TJ, Wroblewski BM. Charnley low-friction arthroplasty in patients with psoriasis. Clin Orthop Relat Res. 1983; Jun;176(176):127-8.

24. Ravi B, Croxford R, Austin PC, Hollands S, Paterson JM, Bogoch E, et al. Increased surgeon experience with rheumatoid arthritis reduces the risk of complications following total joint arthroplasty. Arthritis Rheumatol. 2014; Mar;66(3):488-96.

25. Mortazavi SM, Molligan J, Austin MS, Purtill JJ, Hozack WJ, Parvizi J. Failure following revision total knee arthroplasty: infection is the major cause. Int Orthop. 2011; Aug;35(8):1157-64

26. Le DH, Goodman SB, Maloney WJ, Huddleston Jl. Current modes of failure in TKA: infection, instability, and stiffness predominate. Clin Orthop Relat Res. 2014; Jul;472(7):2197-200.

27. Thiele K, Perka C, Matziolis G, Mayr HO, Sostheim M, Hube R. Current failure mechanisms after knee arthroplasty have changed: polyethylene wear is less common in revision surgery. J Bone Joint Surg Am. 2015; May 6:97(9):715-20.

28. Jamsen E, Huhtala H, Puolakka T, Moilanen T. Risk factors for infection after knee arthroplasty. A register-based analysis of 43,149 cases. J Bone Joint Surg Am. 2009; Jan;91(1):38-47.

29. Kunutsor SK, Whitehouse MR, Blom AW, Beswick AD, INFORM Team. PatientRelated Risk Factors for Periprosthetic Joint Infection after Total Joint Arthroplasty: A Systematic Review and Meta-Analysis. PLoS One. 2016; Mar 3;11(3):e0150866. 
30. Singh JA, Cameron C, Noorbaloochi S, Cullis T, Tucker M, Christensen R, et al. Risk of serious infection in biological treatment of patients with rheumatoid arthritis: a systematic review and meta-analysis. Lancet. 2015; May 11;386(9990):258-65.

31. Shah UH, Mandl LA, Mertelsmann-Voss C, Lee YY, Alexiades MM, Figgie MP, et al. Systemic lupus erythematosus is not a risk factor for poor outcomes after total hip and total knee arthroplasty. Lupus. 2015; Aug;24(9):900-8.

32. Z L LV, Mandl LA, Johnson BK, Figgie MP, Boettner F, Lee $Y Y$, et al. Rheumatoid Arthritis Does Not Increase Risk of Short-term Adverse Events after Total Knee Arthroplasty: A Retrospective Case-control Study. J Rheumatol. 2015; May 1;42(7):1123-30.

33. Johnson BK, Goodman SM, Alexiades MM, Figgie MP, Demmer RT, Mandl LA. Patterns and associated risk of perioperative use of anti-tumor necrosis factor in patients with rheumatoid arthritis undergoing total knee replacement. J Rheumatol. 2013; May;40(5):617-23.

34. George MD, Baker JF, Yenchih Hsu J, Wu Q, Xie F, Chen L, et al. Perioperative timing of infliximab and the risk of serious infection after elective hip and knee arthroplasty. Arthritis Care Res (Hoboken). 2017; Jan 27;69(12):1845-54.

35. Goodman SM, Menon I, Christos PJ, Smethurst R, Bykerk VP. Management of perioperative tumour necrosis factor alpha inhibitors in rheumatoid arthritis patients undergoing arthroplasty: a systematic review and meta-analysis. Rheumatology (Oxford). 2016; Mar;55(3):573-82.

36. Ruyssen-Witrand A, Gossec L, Salliot C, Luc M, Duclos M, Guignard S, et al. Complication rates of 127 surgical procedures performed in rheumatic patients receiving tumor necrosis factor alpha blockers. Clin Exp Rheumatol. 2007; May-Jun;25(3):430-6.

37. Weaver A, Troum O, Hooper M, Koenig AS, Chaudhari S, Feng J, et al. Rheumatoid arthritis disease activity and disability affect the risk of serious infection events in RADIUS 1. J Rheumatol. 2013; Aug;40(8):1275-81.

38. Somayaji R, Barnabe C, Martin L. Risk factors for infection following total joint arthroplasty in rheumatoid arthritis. Open Rheumatol J. 2013; Nov 29;7: 119-24

39. Harpaz R, Ortega-Sanchez I, Seward J. Prevention of Herpes Zoster: Recommendation of the Advisory Committee on Immunization Practices. MMWR. Morbidity and Mortality Weekly Report. 2008;57(05):1-30.

40. Grennan DM, Gray J, Loudon J, Fear S. Methotrexate and early postoperative complications in patients with rheumatoid arthritis undergoing elective orthopaedic surgery. Ann Rheum Dis. 2001; Mar;60(3):214-7.

41. Goodman SM, Springer B, Guyatt G, Abdel MP, Dasa V, George M, et al. 2017 American College of Rheumatology/American Association of Hip and Knee Surgeons Guideline for the Perioperative Management of Antirheumatic Medication in Patients With Rheumatic Diseases Undergoing Elective Total Hip or Total Knee Arthroplasty. Arthritis Rheumatol. 2017; Jun 16;69(8):1111-24

42. Goodman SM, Miller AS, Turgunbaev M, Guyatt G, Yates A, Springer B, et al. Clinical Practice Guidelines: Incorporating Input From a Patient Panel. Arthritis Care Res (Hoboken). 2017; Jun 16:69(8):1125-30.

43. Roman MJ, Moeller E, Davis A, Paget SA, Crow MK, Lockshin MD, et al. Preclinical carotid atherosclerosis in patients with rheumatoid arthritis. Ann Intern Med. 2006; Feb 21;144(4):249-56.

44. Roman MJ, Shanker BA, Davis A, Lockshin MD, Sammaritano L, Simantov R, et al. Prevalence and correlates of accelerated atherosclerosis in systemic lupus erythematosus. N Engl J Med. 2003; Dec 18;349(25):2399-406.

45. Lindhardsen J, Ahlehoff O, Gislason GH, Madsen OR, Olesen JB, TorpPedersen $C$, et al. The risk of myocardial infarction in rheumatoid arthritis and diabetes mellitus: a Danish nationwide cohort study. Ann Rheum Dis. 2011; Jun;70(6):929-34.

46. van Halm VP, Peters MJ, Voskuyl AE, Boers M, Lems WF, Visser M, et al. Rheumatoid arthritis versus diabetes as a risk factor for cardiovascular disease: a cross-sectional study, the CARRE Investigation. Ann Rheum Dis. 2009; Sep;68(9):1395-400.

47. Avina-Zubieta JA, Choi HK, Sadatsafavi M, Etminan M, Esdaile JM, Lacaille D. Risk of cardiovascular mortality in patients with rheumatoid arthritis: a metaanalysis of observational studies. Arthritis Rheum. 2008; Dec 15;59(12):1690-7.

48. Maradit-Kremers $\mathrm{H}$, Crowson CS, Nicola PJ, Ballman KV, Roger VL, Jacobsen SJ, et al. Increased unrecognized coronary heart disease and sudden deaths in rheumatoid arthritis: a population-based cohort study. Arthritis Rheum. 2005; Feb;52(2):402-11.

49. Maradit-Kremers H, Nicola PJ, Crowson CS, Ballman KV, Gabriel SE. Cardiovascular death in rheumatoid arthritis: a population-based study. Arthritis Rheum. 2005; Mar;52(3):722-32.
50. Solomon DH, Kremer J, Curtis JR, Hochberg MC, Reed G, Tsao P, et al. Explaining the cardiovascular risk associated with rheumatoid arthritis: traditional risk factors versus markers of rheumatoid arthritis severity. Ann Rheum Dis. 2010; Nov;69(11):1920-5.

51. Alemao E, Cawston H, Bourhis F, Al M, Rutten-van Molken M, Liao KP, et al. Comparison of cardiovascular risk algorithms in patients with vs without rheumatoid arthritis and the role of C-reactive protein in predicting cardiovascular outcomes in rheumatoid arthritis. Rheumatology (Oxford). 2017; May 1;56(5):777-86.

52. Bernatsky S, Boivin JF, Joseph L, Manzi S, Ginzler E, Gladman DD, et al. Mortality in systemic lupus erythematosus. Arthritis Rheum. 2006; Aug;54(8): 2550-7.

53. Bartels CM, Buhr KA, Goldberg JW, Bell CL, Visekruna M, Nekkanti S, et al. Mortality and cardiovascular burden of systemic lupus erythematosus in a US population-based cohort. J Rheumatol. 2014; Apr;41(4):680-7.

54. Manzi S, Meilahn EN, Rairie JE, Conte CG, Medsger TA Jr, Jansen-McWilliams $L$, et al. Age-specific incidence rates of myocardial infarction and angina in women with systemic lupus erythematosus: comparison with the Framingham Study. Am J Epidemiol. 1997; Mar 1;145(5):408-15.

55. Schoenfeld SR, Kasturi S, Costenbader KH. The epidemiology of atherosclerotic cardiovascular disease among patients with SLE: a systematic review. Semin Arthritis Rheum. 2013; Aug;43(1):77-95.

56. Fernandez-Nebro A, Rua-Figueroa I, Lopez-Longo FJ, Galindo-Izquierdo M, Calvo-Alen J, Olive-Marques A, et al. Cardiovascular Events in Systemic Lupus Erythematosus: A Nationwide Study in Spain From the RELESSER Registry. Medicine (Baltimore). 2015; Jul;94(29):e1183.

57. Esdaile JM, Abrahamowicz M, Grodzicky T, Li Y, Panaritis C, du Berger R, et al. Traditional Framingham risk factors fail to fully account for accelerated atherosclerosis in systemic lupus erythematosus. Arthritis Rheum. 2001; Oct; 44(10):2331-7.

58. Karp I, Abrahamowicz M, Fortin PR, Pilote L, Neville C, Pineau CA, et al. Recent corticosteroid use and recent disease activity: independent determinants of coronary heart disease risk factors in systemic lupus erythematosus? Arthritis Rheum. 2008; Feb 15;59(2):169-75.

59. Wibetoe G, Ikdahl E, Rollefstad S, Olsen IC, Bergsmark K, Kvien TK, et al. Cardiovascular disease risk profiles in inflammatory joint disease entities. Arthritis Res Ther. 2017; Jul 3;19(1):153. 017-1358-1

60. Han C, Robinson DW Jr, Hackett MV, Paramore LC, Fraeman KH, Bala MV. Cardiovascular disease and risk factors in patients with rheumatoid arthritis, psoriatic arthritis, and ankylosing spondylitis. J Rheumatol. 2006; Nov;(11):33, 2167-2172.

61. Haque N, Lories RJ, de Vlam K. Comorbidities Associated with Psoriatic Arthritis Compared with Non-psoriatic Spondyloarthritis: A Cross-sectional Study. J Rheumatol. 2016; Feb;43(2):376-82.

62. Ogdie A, Yu Y, Haynes K, Love TJ, Maliha S, Jiang Y, et al. Risk of major cardiovascular events in patients with psoriatic arthritis, psoriasis and rheumatoid arthritis: a population-based cohort study. Ann Rheum Dis. 2015; Feb;74(2):326-32.

63. Urban MK, Jules-Elysee K, Loughlin C, Kelsey W, Flynn E. The one year incidence of postoperative myocardial infarction in an orthopedic population. HSS J. 2008; Feb;4(1):76-80.

64. Innala L, Moller B, Ljung L, Magnusson S, Smedby T, Sodergren A, et al. Cardiovascular events in early RA are a result of inflammatory burden and traditional risk factors: a five year prospective study. Arthritis Res Ther. 2011; Aug 15;13(4):R131.

65. Peters MJ, van der Horst-Bruinsma IE, Dijkmans BA, Nurmohamed MT. Cardiovascular risk profile of patients with spondylarthropathies, particularly ankylosing spondylitis and psoriatic arthritis. Semin Arthritis Rheum. 2004; Dec;34(3):585-92.

66. Domsic RT, Lingala B, Krishnan E. Systemic lupus erythematosus, rheumatoid arthritis, and postarthroplasty mortality: a cross-sectional analysis from the nationwide inpatient sample. J Rheumatol. 2010; Jul;37(7):1467-72.

67. Babazade R, Yilmaz HO, Leung SM, Zimmerman NM, Turan A. Systemic Lupus Erythematosus Is Associated With Increased Adverse Postoperative Renal Outcomes and Mortality: A Historical Cohort Study Using Administrative Health Data. Anesth Analg. 2017; Apr;124(4):1118-26.

68. Fleisher LA, Fleischmann KE, Auerbach AD, Barnason SA, Beckman JA, Bozkurt B, et al. 2014 ACC/AHA guideline on perioperative cardiovascular evaluation and management of patients undergoing noncardiac surgery: executive summary: a report of the American College of Cardiology/ American Heart Association Task Force on practice guidelines. Developed in 
collaboration with the American College of Surgeons, American Society of Anesthesiologists, American Society of Echocardiography, American Society of Nuclear Cardiology, Heart Rhythm Society, Society for Cardiovascular Angiography and Interventions, Society of Cardiovascular Anesthesiologists, and Society of Vascular Medicine Endorsed by the Society of Hospital Medicine. J Nucl Cardiol. 2015; Feb;22(1):162-215.

69. Jette M, Sidney K, Blumchen G. Metabolic equivalents (METS) in exercise testing, exercise prescription, and evaluation of functional capacity. Clin Cardiol. 1990; Aug;13(8):555-65.

70. Mirfeizi Z, Poorzand H, Javanbakht A, Khajedaluee M. Relationship Between Systemic Lupus Erythematosus Disease Activity Index Scores and Subclinical Cardiac Problems. Iran Red Crescent Med J. 2016; Jul 17;18(8):e38045.

71. Divard G, Abbas R, Chenevier-Gobeaux C, Chanson N, Escoubet B, Chauveheid MP, et al. High-sensitivity cardiac troponin $\mathrm{T}$ is a biomarker for atherosclerosis in systemic lupus erythematous patients: a cross-sectional controlled study. Arthritis Res Ther. 2017; Jun 13;19(1):132,017-1352-7.

72. Mosca L, Benjamin EJ, Berra K, Bezanson JL, Dolor RJ, Lloyd-Jones DM, et al. Effectiveness-based guidelines for the prevention of cardiovascular disease in women-2011 update: a guideline from the american heart association. Circulation. 2011; Mar 22;123(11):1243-62.

73. Agca R, Heslinga SC, Rollefstad S, Heslinga M, Mclnnes IB, Peters MJ, et al. EULAR recommendations for cardiovascular disease risk management in patients with rheumatoid arthritis and other forms of inflammatory joint disorders: 2015/2016 update. Ann Rheum Dis. 2017; Jan;76(1):17-28.

74. Crowson CS, Gabriel SE, Semb AG, van Riel PL, Karpouzas G, Dessein PH, et al. Rheumatoid arthritis-specific cardiovascular risk scores are not superior to general risk scores: a validation analysis of patients from seven countries. Rheumatology (Oxford). 2017; Mar 8;56(7):1102-10,

75. Arts EE, Popa CD, Den Broeder AA, Donders R, Sandoo A, Toms T, et al. Prediction of cardiovascular risk in rheumatoid arthritis: performance of original and adapted SCORE algorithms. Ann Rheum Dis. 2016; Apr;75(4): 674-80.

76. Semb AG, Ikdahl E, Hisdal J, Olsen IC, Rollefstad S. Exploring cardiovascular disease risk evaluation in patients with inflammatory joint diseases. Int J Cardiol. 2016; Nov 15;223:331-6.

77. Johannesdottir SA, Schmidt M, Horvath-Puho E, Sorensen HT. Autoimmune skin and connective tissue diseases and risk of venous thromboembolism: a population-based case-control study. J Thromb Haemost. 2012; May; 10(5): 815-21.

78. Kim SC, Schneeweiss S, Liu J, Solomon DH. Risk of venous thromboembolism in patients with rheumatoid arthritis. Arthritis Care Res (Hoboken). 2013; Oct;65(10):1600-7.

79. Zoller B, Li X, Sundquist J, Sundquist K. Risk of pulmonary embolism in patients with autoimmune disorders: a nationwide follow-up study from Sweden. Lancet. 2012; Jan 21:379(9812):244-9.

80. Ramagopalan SV, Wotton CJ, Handel AE, Yeates D, Goldacre MJ. Risk of venous thromboembolism in people admitted to hospital with selected immune-mediated diseases: record-linkage study. BMC Med. 2011; Jan 10; 9(1):7015-9-1.

81. Yusuf HR, Hooper WC, Beckman MG, Zhang QC, Tsai J, Ortel TL. Risk of venous thromboembolism among hospitalizations of adults with selected autoimmune diseases. J Thromb Thrombolysis. 2014; Oct;38(3):306-13.

82. Xu J, Lupu F, Esmon CT. Inflammation, innate immunity and blood coagulation. Hamostaseologie. 2010; Jan;30(1):5,6, 8-9.

83. Bacani AK, Gabriel SE, Crowson CS, Heit JA, Matteson EL. Noncardiac vascular disease in rheumatoid arthritis: increase in venous thromboembolic events? Arthritis Rheum. 2012; Jan;64(1):53-61.

84. Choi HK, Rho YH, Zhu Y, Cea-Soriano L, Avina-Zubieta JA, Zhang Y. The risk of pulmonary embolism and deep vein thrombosis in rheumatoid arthritis: a UK population-based outpatient cohort study. Ann Rheum Dis. 2013; Jul; 72(7):1182-7.

85. Matta F, Singala R, Yaekoub AY, Najjar R, Stein PD. Risk of venous thromboembolism with rheumatoid arthritis. Thromb Haemost. 2009; Jan; 101(1):134-8.

86. Sun Z, Hesler BD, Makarova N, Dalton JE, Doan M, Moraska A, et al. The Association Between Rheumatoid Arthritis and Adverse Postoperative Outcomes: A Retrospective Analysis. Anesth Analg. 2016; Jun;122(6):1887-93.

87. Wei J, Li W, Pei Y, Shen Y, Li J. Clinical analysis of preoperative risk factors for the incidence of deep venous thromboembolism in patients undergoing posterior lumbar interbody fusion. J Orthop Surg Res. 2016; Jun 13;11(1):68,016-0403-0.
88. Cancienne JM, Werner BC, Browne JA. Complications of Primary Total Knee Arthroplasty Among Patients With Rheumatoid Arthritis, Psoriatic Arthritis, Ankylosing Spondylitis, and Osteoarthritis. J Am Acad Orthop Surg. 2016; Aug;24(8):567-74

89. Mok CC, Tang SS, To CH, Petri M. Incidence and risk factors of thromboembolism in systemic lupus erythematosus: a comparison of three ethnic groups. Arthritis Rheum. 2005; Sep;(9):52, 2774-2782.

90. Calvo-Alen J, Toloza SM, Fernandez M, Bastian HM, Fessler BJ, Roseman JM, et al. Systemic lupus erythematosus in a multiethnic US cohort (LUMINA). XXV. Smoking, older age, disease activity, lupus anticoagulant, and glucocorticoid dose as risk factors for the occurrence of venous thrombosis in lupus patients. Arthritis Rheum. 2005; Jul;52(7):2060-8.

91. Habe K, Wada H, Matsumoto T, Ohishi K, Ikejiri M, Matsubara K, et al. Presence of Antiphospholipid Antibodies as a Risk Factor for Thrombotic Events in Patients with Connective Tissue Diseases and Idiopathic Thrombocytopenic Purpura. Intern Med. 2016;55(6):589-95.

92. Pengo V, Ruffatti A, Legnani C, Gresele P, Barcellona D, Erba N, et al. Clinical course of high-risk patients diagnosed with antiphospholipid syndrome. J Thromb Haemost. 2010; Feb;8(2):237-42.

93. Sciascia S, Cuadrado MJ, Sanna G, Murru V, Roccatello D, Khamashta MA, et al. Thrombotic risk assessment in systemic lupus erythematosus: validation of the global antiphospholipid syndrome score in a prospective cohort. Arthritis Care Res (Hoboken). 2014; Dec;66(12):1915-20.

94. Reynaud Q, Lega JC, Mismetti P, Chapelle C, Wahl D, Cathebras P, et al. Risk of venous and arterial thrombosis according to type of antiphospholipid antibodies in adults without systemic lupus erythematosus: a systematic review and meta-analysis. Autoimmun Rev. 2014; Jun;13(6):595-608.

95. Saunders KH, Erkan D, Lockshin MD. Perioperative management of antiphospholipid antibody-positive patients. Curr Rheumatol Rep. 2014; Jul; 16(7):426. 014-0426-7

96. Raso S, Sciascia S, Kuzenko A, Castagno I, Marozio L, Bertero MT. Bridging therapy in antiphospholipid syndrome and antiphospholipid antibodies carriers: case series and review of the literature. Autoimmun Rev. 2015; Jan; 14(1):36-42.

97. Cohen H, Hunt BJ, Efthymiou M, Arachchillage DR, Mackie IJ, Clawson S, et al. Rivaroxaban versus warfarin to treat patients with thrombotic antiphospholipid syndrome, with or without systemic lupus erythematosus (RAPS): a randomised, controlled, open-label, phase 2/3, non-inferiority trial. Lancet Haematol. 2016; Sep;3(9):e426-36.

98. Cervera R. CAPS Registry Project Group. Catastrophic antiphospholipid syndrome (CAPS): update from the 'CAPS Registry'. Lupus. 2010; Apr;19(4): $412-8$.

\section{Submit your next manuscript to BioMed Central and we will help you at every step:}

- We accept pre-submission inquiries

- Our selector tool helps you to find the most relevant journal

- We provide round the clock customer support

- Convenient online submission

- Thorough peer review

- Inclusion in PubMed and all major indexing services

- Maximum visibility for your research

Submit your manuscript at www.biomedcentral.com/submit
) Biomed Central 